\title{
Emergency medicine training in Canada survey
}

\author{
1. Part 1 \\ 1. Please indicate your sex \\ Male \\ Female \\ Other
}

Medical students' preferences, knowledge and attitudes regarding EM

2. Please indicate your age
O $<20$
○20-24
○25-29
○ $30+$

3. What is the approximate population of the city/town in which you spent the majority of your life?

$\bigcirc<10,000$

○ $10,000-49.999$

○ $50,000-99,999$

(100,000-500,000

$\bigcirc>500,000$

4. Do you have any children?

Yes
No
choose not to answer

5. What is your relationship status?
Single
Married
choose not to answer
Other (please specty) 


\section{Medical students' preferences, knowledge and attitudes regarding EM}

6. What is the highest level of education you have obtained?
High school
College diploma
Bachelor's degree
Master's degree
$\bigcirc$ PhD.
Other (please specify)

7. Which year of medical study are you in?
1styeer
2nd year
3rd year
4th year

\section{Part 2a}

Please answer these questions to the best of your ability.

1. How many different residency training stream(s) are there to obtain certification as an emergency physician in Canada?
O
$\mathrm{O}_{1}$
$\mathrm{O}_{2}$
○
$\mathrm{O}_{4} \mathrm{O}_{5}$
Unsure

2. How many college(s) govern the emergency medicine training stream(s)?
O
$\bigcirc$
$\mathrm{O}_{2}$
$\mathrm{O}_{3} \mathrm{O}_{4}$
$\bigcirc$
$\bigcirc$ Unsure

\section{Part 2b}

There are currently two emergency residency training streams governed by 2 separate colleges: The Royal College of Physicians stream (FRCPC) and the College of Canadian Family Physicians (CCFP-EM).

1. Please indicate the TOTAL number of years you believe it takes to complete the Royal College of Physicians of Canada (FRCPC) residency training program for emergency medicine certification.
$\bigcirc$
$\mathrm{O}^{2}$
$\mathrm{O}_{3}$
$\mathrm{O}_{4}$
$\mathrm{O}_{5}$
$\bigcirc>5$
Uneure 


\section{Medical students' preferences, knowledge and attitudes regarding EM}

2. Please indicate the TOTAL number of years you believe it takes to complete the Family Medicine (CCFP-EM) residency training program for emergency medicine certification.
$\bigcirc$
$\mathrm{O}^{2}$
$\mathrm{O}_{3}$
$\bigcirc_{4}$
O
$\bigcirc>5$
$\bigcirc$ Uneure

3. Are graduates of the Royal College stream of emergency medicine allowed to work in family practice?
Yres
No
Unsure

4. Are graduates of the Family Medicine stream in emergency medicine allowed to work in tertiary care centres?
Pres
No
Unsure

5. Which of the two residency training streams do you believe gives more exposure to the following areas during the training process? Note: CCFP-EM = Family Medicine stream, FRCPC = Royal College stream.

ER Medicine
Family Medicine
Teaching Opportunities
Rural Medicine
Research Opportunities
Emergency Subspecialty Opportunities (ex. T
Toxicology)
6. Do you believe that graduate
equally?
Yes, they are paid equally
No, CCFP.EM graduates are paid more
Unsure

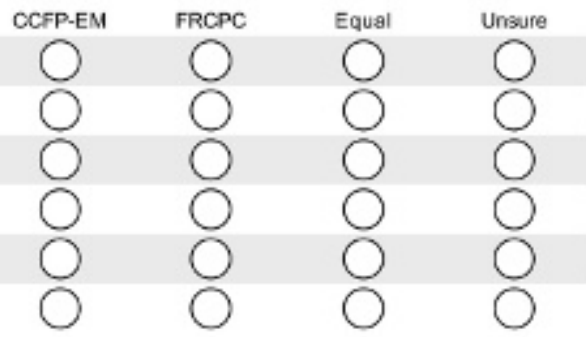




\section{Medical students' preferences, knowledge and attitudes regarding EM}

7. Do you believe that graduates from the two different training streams work the same average number of hours on a weekly basis?

Yes, they work equal hours

No, FRCPC greduates work more hours

No, CCFP.EM graduates work more hours

Unsure

8. Do you believe that graduates from the two different training streams experience equal "burnout"?

Yes, thoy experisnce equal burnout

No, CCFP EM gratustes experience more burnout

No, FRCPC graduates experience more "burnout"

Unsure

\section{Part 3}

Please note: the wording of questions in parts 3 and 4 have been adapted to suit both 4 th year students who have applied to residency programs and 1 st, 2nd and 3rd year students who have yet to apply.

1. Are you interested in applying to or have you applied to emergency medicine for your residency training program?
Y res
No
Unsure

\section{Part 3a}

1. Which stream are you MOST interested in applying to at this point? (For 4th year students, please indicate which stream you have applied to).

CCFP.EM

FRCPC

Unsure

\section{Part 3b}




\section{Medical students' preferences, knowledge and attitudes regarding EM}

1. Please select the amount of time you intend to spend working in emergency medicine vs. the amount of time you intent to spend working in family medicine.

All emergency medicine

Mostly emergency medicine

Half and half

Mostly family medicine

All family medicine

\section{Part 3c}

1. Do you intend to also apply to or have you also applied to the CCFP-EM stream in order to improve your chances of obtaining and Emergency Medicine residency training position?

Yes

No

Unsura

\section{Part 4a}




\section{Medical students' preferences, knowledge and attitudes regarding EM}

1. For each of the following statements, please indicate whether you...

Strongly Disagree, Disagree, are Neutral, Agree, or Strongly Agree

\begin{tabular}{|c|c|c|c|c|}
\hline & $\begin{array}{l}\text { Strongly } \\
\text { Disagrea }\end{array}$ & Disagree & Neutral & Agree \\
\hline \multicolumn{5}{|l|}{$\begin{array}{l}\text { My choeen stream will allow me to have control over my work schedule } \\
\text { during my career. }\end{array}$} \\
\hline \multicolumn{5}{|l|}{$\begin{array}{l}\text { My chosen stream will give me statusiprestige among my metical } \\
\text { colleggues. }\end{array}$} \\
\hline \multicolumn{5}{|l|}{$\begin{array}{l}\text { Ability to spend time with my family will be/was a factor in my choice } \\
\text { of emergency medicine stream. }\end{array}$} \\
\hline \multicolumn{5}{|l|}{ My chosen stream will allow me to conduct research. } \\
\hline \multicolumn{5}{|l|}{$\begin{array}{l}\text { My chosen stream will allow me to develop long-term relationships } \\
\text { with my patients. }\end{array}$} \\
\hline \multicolumn{5}{|l|}{$\begin{array}{l}\text { My chosen stream will allow me to pursue an academic appointment } \\
\text { at a medical teaching facility. }\end{array}$} \\
\hline \multicolumn{5}{|l|}{$\begin{array}{l}\text { A mentor encouraged me to apply to my chosen emergency medicine } \\
\text { strearm. }\end{array}$} \\
\hline \multicolumn{5}{|l|}{$\begin{array}{l}\text { A mentor discouraged me from applying to the other emergency } \\
\text { medicine stream. }\end{array}$} \\
\hline \multicolumn{5}{|l|}{$\begin{array}{l}\text { Ease of entry into residency will beiwas a factor in my choice of } \\
\text { emergency medicine stream. }\end{array}$} \\
\hline \multicolumn{5}{|l|}{$\begin{array}{l}\text { Income potential will be/was a tactor in my choice of emergency } \\
\text { medicine stream. }\end{array}$} \\
\hline \multicolumn{5}{|l|}{$\begin{array}{l}\text { The possibility of "ourning oul" will belwas a facter in my choice of } \\
\text { emergency medicine stream. }\end{array}$} \\
\hline \multicolumn{5}{|l|}{$\begin{array}{l}\text { My chosen stroam will allow me adequate time to gain expertise in all } \\
\text { areas of emergency medicine by the end of my residency. }\end{array}$} \\
\hline \multicolumn{5}{|l|}{$\begin{array}{l}\text { A shorter resicency will be/was a factor in my choice of emergency } \\
\text { medicine stream. }\end{array}$} \\
\hline \multicolumn{5}{|l|}{$\begin{array}{l}\text { My chosen stream will allow me the opportunity to subspecialize within } \\
\text { the field of emergency medicine (ex, toxicology, traumatology). }\end{array}$} \\
\hline My chosen stream will allow me to work in a nural community. & & & & \\
\hline
\end{tabular}

\section{Part 4b}




\section{Medical students' preferences, knowledge and attitudes regarding EM}

1. From the following list of factors, please rank the 5 that are/were the most influential in determining your choice of residency stream within emergency medicine. (Please select "1st" for the most influential factor, "2nd" for the second most influential factor, "3rd" for the third most influential factor, etc.)

Bumout prevention
Control over work sctecule
Developing long-term relationships with patients
Ease of residency entry
Expertise in emergency medicine
Family life
Income potential
Mentor discouragement
Mrentor encourage
Research opportunities
Shorter residency program
Subspecialization opportunities (ex. Traumatology, toxieology)
Teaching opportunities
Working in a rural commer
(plesse speciry)

\section{Part 5}

1. Do you believe that there should be two streams to become a licensed emergency physician in Canada?

$\bigcirc$ res

No

Unsure 
Medical students' preferences, knowledge and attitudes regarding EM

2. Do you believe that residents from both streams are equally competent in emergency medicine upon graduation from their residency stream?

Yes, they are equally competent
No, CCFP-EM physicians are more competent
No, FRCPG physicians are more competent
Unsure

3. Do you believe that residents from both streams who work full time in emergency medicine are equally competent in emergency medicine five years after completion of their residency training?
(Yes, they are equally competent
No, FRCPC physicilans are more competent
(No, CCFP-EM physicians are more competent
(1) Unsure

4. Do you believe the FRCPC (Royal College) emergency medicine residency training program should be shorter than five years?
Y Yes
Na
(C) Unsure

5. Do you believe the CCFP-EM (Family Medicine) emergency medicine residency training program should be longer than two years of family medicine training plus one extra year for emergency medicine training?
Yyes
No
(ansure 
Medical students' preferences, knowledge and attitudes regarding EM

6. Do you believe that physicians and other hospital staff regard and/or treat emergency medicine RESIDENTS differently depending on their residency stream?

(No, they are treated equally
Yas, CCFP-EM residents are treated preferentially
Yes, FRCPC residents are treated preferentially
Unsure

7. Do you believe that physicians and other hospittal staff regard and/or treat emergency medicine PHYSICIANS differently depending on the residency training stream from which they graduated?
(No, they are treated equally
(Yes, FRCPC trained physictians are treated preferentially
Y Yas, CCFP-EM traîned physicieians are treated preferentially
( Unsure

8. If you decided to apply to the CCFP (Family Medicine) residency training program, would you disclose your intentions of pursuing the extra emergency medicine training year in your interview?
( Yes
( No
(C) Unsure
Not Applicable

9. Do you believe it is acceptable for residents to complete the CCFP-EM stream with the intention of practicing solely emergency medicine?
Q Yes
Ono
Unsure 


\section{Medical students' preferences, knowledge and attitudes regarding EM}

10. Which college do you feel should fund the additional emergency medicine training year for CCFP-EM residents?

Canadian College of Family Physicians (CCFP)

( Rayal Callege of Physicians (FRCPC)

Both

Unsure 